\title{
GRAPHICAL-AND-ANALYTICAL BASIS FOR QUANTOMOBILE NEAR-GROUND MOTION STUDIES
}

\author{
Jurij Kotikov \\ Saint Petersburg State University of Architecture and Civil Engineering \\ Vtoraja Krasnoarmejskaja st., 4, St. Petersburg, Russia \\ Email: cotikov@mail.ru
}

\begin{abstract}
Introduction. Development of a graphical-and-analytical basis to perform optimization calculations for quantomobile motion control will contribute to studies on vehicle creation. Purpose of the study. It is required to develop a methodology for graphical representation of thrust vector realization as a graphical-and-analytical basis for optimization calculations of quantomobile trajectories. Methods. The thrust vector is decomposed into orthogonal components. A generalized quantomobile force balance equation is used. A mode of partial hovering of a vehicle is distinguished as the basic mode of near-ground motion. 2D modeling of force balance for a particular velocity slice is performed. 3D modeling of force balance with velocity sweeping is carried out. 2D and 3D models of force balance are developed using Maple software. Images of surfaces with regard to road and wind resistance with limits to the maximum thrust are built. Examples of calculation as well as graphical-and-analytical studies are provided. Results. A graphical-and-analytical basis for optimization calculations of quantomobile trajectories, changes in QE thrust and corresponding control actions is developed. Results of calculations with visualization are presented using specific examples. Discussion. Development of a program in the graphical environment required combining knowledge of the software tools and programmed field. Development of the quantomobile simulation model as well as its graphical-and-analytical basis in the direction of increasing complexity is the only way. Corresponding development stages are described. Two hypothetical areas for the minimization of sufficient thrust are distinguished: in the middle of vehicle hovering and after its full hovering. It shall be taken into account both in quantomobile takeoff and its near-ground motion with partial hovering.
\end{abstract}

\section{Keywords}

Quantum engine, quantum thrust, quantomobile, near-ground motion, force balance, graphical-and-analytical basis

\section{Introduction}

Extraction of energy from the physical vacuum (Leonov, 2002, 2010, 2018) will change the motion mechanics of vehicles equipped with quantum engines (QEs). In contrast to ICEs, QEs generate thrust, which can be applied directly to the vehicle body to create motion (Leonov, 2010, Brandenburg, 2017, Tajmar, 2007).

Changing the thrust vector position from horizontal to inclined will make it possible to create a vertical component of thrust, which can be used to overcome gravitation and get the quantomobile above the bearing surface (Kotikov, 2018a).

In earlier papers (Kotikov, 2018a, 2018b, 2018c, 2019a, $2019 b, 2019 c)$, the author described individual aspects of vehicle force balance. Development of a graphical-andanalytical basis to design control over QE thrust and vehicle motion will contribute to further studies on this topic.

\section{Purpose and tasks of the study}

1. To develop a methodology for 2D and 3D graphical representation of thrust vector realization in the pitch plane as a graphical-and-analytical basis for future optimization calculations of quantomobile trajectories, changes in $\mathrm{QE}$ thrust, and corresponding control actions. 2. To consider specifics of using the generalized quantomobile force balance equation (derived by the author) when modeling the vehicle near-ground motion. 3 . To provide numerical and graphical examples. 4. To discuss results and prospects for further development.

\section{Methods}

Thrust vector decomposition

The thrust vector in the pitch plane can be decomposed into unit vectors (Leonov, 2018, Kotikov, 2019c):

$$
F_{T}=F_{T x}+F_{T z}
$$


The scalar form of this equation is as follows:

$$
F_{T}=\sqrt{F_{T x}^{2}+F_{T z}^{2}}
$$

The first quadrant of the circle formed by the thrust vector tip corresponds to the translational motion of the quantomobile (Fiqure 1).

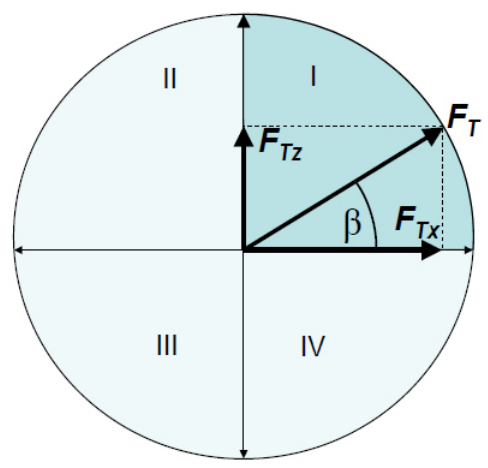

Figure 1. Decomposition of $\boldsymbol{F}_{T}$ thrust into horizontal $\left(\boldsymbol{F}_{T_{x}}\right)$ and vertical $\left(\boldsymbol{F}_{T_{Z}}\right)$ components: $\beta-\boldsymbol{F}_{T}$ thrust inclination angle

Quantomobile and automobile force balance analyses differ. This is due to the fact that the quantomobile force balance equation involves entities, which are unique for land vehicles and manifest when vertical forces (gravity, hovering, wind resistance to vertical motion, vertical accelerations) are taken into account.

These aspects are considered in aircraft and helicopter engineering with regard to vertical takeoff and landing (VTOL) as well as short takeoff and landing (STOL) (Schmitz, 1971, Cerbe and Reichert, 1989, Century of Flight, 2007). Let us develop a unique model based on that experience.

\section{Generalized quantomobile force balance equation and its reductions}

As a result of equation (2) detalization, we obtain the following (Kotikov, 2019c):

$$
\begin{aligned}
& F_{T}^{2}=F_{T_{x}}{ }^{2}+F_{T_{z}}{ }^{2}=\left(P_{f}+P_{w . x}+P_{j . x}\right)^{2}+\left(P_{w . z}+P_{j . z}+P_{g}\right)^{2}= \\
& \left(\left.f_{\text {wh. } .}\left(1+f_{\text {wh. } v} \cdot V_{x}^{2}\right) \cdot\left(G_{q}-F_{T_{z}}\right)\right|_{F_{z} \leq G_{q}}+k_{w x} \cdot S_{\text {front }} \cdot V_{w}{ }^{2}+\frac{G_{q}}{g} a_{x} \cdot\left(1+\delta_{w h}\right)\right)^{2}+ \\
& +\left(\left.\left(k_{w z} \cdot S_{p l a n} \cdot V_{z}^{2}+\frac{G_{q}}{g} a_{z}\right)\right|_{F_{z z}>G_{q}}+\min \left(F_{T_{z}}, G_{q}\right)\right)^{2},
\end{aligned}
$$

where:

$P_{f}-$ a force of resistance to the rolling of wheels, $\mathrm{N}$; $P_{w x}^{f}$ - wind resistance to the horizontal motion, N; $P_{j x}^{w . x}-a$ force of resistance to horizontal acceleration, $\mathrm{N}$; $P_{w . z}^{j . x}$ - wind resistance to the vertical motion, $\mathrm{N}$; $P_{i . z}^{w . z}-$ a force of resistance to vertical acceleration, $\mathrm{N}$; $P_{g}^{J . z}=\min \left(F_{T z}, G_{q}\right)$ - a part of the vertical component of thrust used to neutralize $\mathrm{g}$ portion of hovering vehicle's gravity $\left(y=F_{T z} / G_{q}\right), \mathrm{N}$; $f_{\text {wh. } 0}-$ a coefficient of resistance to the rolling of driven wheels at a speed close to zero, and $F_{T Z}=0$;

$f_{\text {wh.v }}-$ a velocity coefficient of resistance to the rolling of driven wheels;

$V_{x}$ - velocity of longitudinal (course) motion of the vehicle, $\mathrm{m} / \mathrm{s}$;

$\mathrm{G}_{q}$ - quantomobile weight, $\mathrm{N}$

$k_{w . x}^{q}-$ a horizontal (longitudinal) wind shape coefficient, $\mathrm{N} \times \mathrm{s}^{2} / \mathrm{m}^{4}$;

$S_{\text {front }}-$ frontal area of the vehicle, $\mathrm{m}^{2}$;

$V_{w}-$ longitudinal velocity of the vehicle relative to the wind (in the present study, $V_{w}=V_{x}$ ), $\mathrm{m} / \mathrm{s}$;

$g$ - gravitational acceleration, $\mathrm{m} / \mathrm{s}^{2}$;

$a_{x}$ - longitudinal acceleration of the vehicle, $\mathrm{m} / \mathrm{s}^{2}$;

$\delta_{w h}^{x}$ - a rotational inertia coefficient of driven carrying wheels;

$k_{w z}-$ a vertical wind shape coefficient, $\mathrm{N} \times \mathrm{s}^{2} / \mathrm{m}^{4}$;

$S_{\text {plan }}-$ vehicle area in plan view, $\mathrm{m}^{2}$;

$V_{z}-$ vertical motion velocity of the vehicle, $\mathrm{m} / \mathrm{s}$;

$a_{z}$ - vertical acceleration of the vehicle, $\mathrm{m} / \mathrm{s}^{2}$;

| $F_{T z} \leq G_{q}$ - a range of $F_{T z}$ values in the mode of partial hovering of the vehicle;

| $F_{T z}>G_{q}$ - a range of $F_{T z}$ values in the mode of full hovering of the vehicle (with possible breakoff from the bearing surface).

When considering force balance in uniform steady motion, upon contact with the bearing surface but without breakoff (at $F_{T z} \leq G_{q}$ ), it is possible to use the following reduced equation:

$$
\begin{aligned}
& F_{T}{ }^{2}=F_{T x}{ }^{2}+F_{T z}^{2}=\left(P_{f}+P_{w x}\right)^{2}+\left(P_{w z}+P_{g}\right)^{2}= \\
& =\left(f_{w h .}\left(1+f_{w h l v} \cdot V_{x}^{2}\right) \cdot\left(G_{q}-F_{T_{z}}\right)+k_{w x} \cdot S_{\text {from }} \cdot V_{x}^{2}\right)^{2}+\left(k_{w z} \cdot S_{p l a n} \cdot V_{z}^{2}+F_{T_{z}}\right)^{2} .
\end{aligned}
$$

Moreover, if we take the vertical motion velocity $V_{z}$ as negligible (as compared with $V_{x}$ ), the equation can be reduced to the following form:

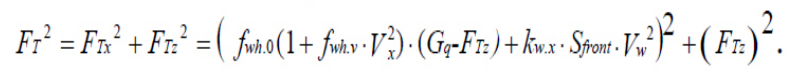

Equation (5) is implicit with regard to $x=F_{T x}, z=F_{T z}$, $y=V_{x}$ arguments. In case of calculation studies, explicit equations may be required.

Equation (5) can be reduced to the explicit form with regard to $F_{T x}$ :

$$
F_{T x}=\left(f_{w h .0}\left(1+f_{w h . v} \cdot V_{x}^{2}\right) \cdot\left(G_{q}-F_{T z}\right)+k_{w . x} \cdot S_{f r o n t} \cdot V_{x}^{2}\right) .
$$

with regard to $F_{\mathrm{Tz}}$ :

$$
F_{T z}=G_{q}+\frac{k_{w . x} \cdot S_{f r o n t} \cdot V_{x}^{2}-F_{T x}}{f_{w h .0}\left(1+f_{w h . v} \cdot V_{x}^{2}\right)} .
$$

with regard to $V_{x}$ : 


$$
V_{x}=\sqrt{\frac{F_{T x}-f_{w h .0}\left(G_{q}-F_{T z}\right)}{f_{w h .0} \cdot f_{w h . v}\left(G_{q}-F_{T z}\right)+k_{w . x} \cdot S_{f r o n t}}} .
$$

With account for $Y=F_{T z} / G_{q}$, after $\left(G_{q}-F_{T z}\right)=G_{q}(1-\gamma)$ substitution, equation (8) will take the following form:

$$
V_{x}=\sqrt{\frac{F_{T x}-f_{w h .0} \cdot G_{q} \cdot(1-\gamma)}{f_{w h .0} \cdot f_{w h . v} \cdot G q \cdot(1-\gamma)+k_{w . x} \cdot S_{f r o n t}}} .
$$

When analyzing the moment of quantomobile breakoff from the bearing surface $\left(F_{T z}=G_{q}\right)$, accepting that $\delta_{w h}=0, V_{z}=0, a_{z}=0$, equation (3) can be reduced to the following form:

$$
F_{T}^{2}=F_{T_{x}}^{2}+F_{T_{z}}^{2}=\left(k_{w x} \cdot S_{\text {front } t V_{x}}^{2}+\frac{G_{q}}{g} a_{x}\right)^{2}+\left(G_{q}\right)^{2} .
$$

Taking into account that $F_{T 2}=G_{q}$, the balance of horizontal forces can be simplified as follows:

$$
F_{T x}=k_{w . x} \cdot S_{\text {front } \cdot V_{x}}{ }^{2}+\frac{G_{q}}{g} a_{x} .
$$

If the balance conditions in equation (11) are maintained, the following can be written for the longitudinal acceleration of a vehicle in the mode of full hovering (at $F_{T z}=G_{q}$ ):

$$
a_{x}=\frac{g}{G_{a}}\left(F_{T x}-k_{w \cdot x} \cdot S_{\text {front }} \cdot V_{x}^{2}\right) .
$$

The maximum possible velocity of a hovering vehicle can be determined by setting $a_{x}=0$ :

$$
V_{x . \max }=\sqrt{F_{T x} / k_{w . x} \cdot S_{\text {front }}} .
$$

The acceleration at the initial moment of longitudinal motion of a hovering vehicle can be determined by setting $v_{x}=0$ :

$$
a_{x}=\frac{F_{T x} \cdot g}{G_{q}} .
$$

We can complement the analysis based on equations (1)-(14) with corresponding graphical models.

\section{Thrust representation for a particular velocity slice. 2D modeling}

Figure 1 shows a calculation example and graphical representation for a particular quantomobile force balance.
Let us analyze a hypothetical quantomobile having specifications of a similar automobile (KamAZ-4326) with a QE, under extremely severe conditions of motion: $G_{q}=$ $88 \mathrm{kN} ; f_{\text {wh.o }}=0.3 ; f_{\text {wh. } . v}=4 \times 10-4 \mathrm{~s}^{2} / \mathrm{m}^{2} ; k_{w . x}=0.5 \mathrm{~N} \times \mathrm{s}^{2} / \mathrm{m}^{4}$; $S_{\text {front }}=7 \mathrm{~m}^{2} ; \delta_{K}=0.04 ; k_{w . z}=0.8 \mathrm{~N} \times \mathrm{s}^{2} / \mathrm{m}^{4} ; S_{\text {plan }}=17.5 \mathrm{~m}^{2}$ (Kotikov, 2019a, 2019b).

We consider a situation where a practical coincidence of the thrust values is observed: for steady motion at a speed of $67.2 \mathrm{~m} / \mathrm{s}$ in the automobile mode $\left(F_{T z}=0\right.$, $\left.F_{T}=F_{T x}=89.9 \mathrm{kN}\right)$ and for full hovering of the vehicle $\left(F_{T}=\left(F_{T z}^{2}+F_{T x}^{2}\right)^{1 / 2}=\left(88^{2}+15.8^{2}\right)^{1 / 2}=89.4 \mathrm{kN}\right)$ (Figure 2). In an earlier paper (Kotikov, 2019c), the following was quantitatively substantiated: at $f_{\text {wh.o }}=0.3$, the course speed of $67.2 \mathrm{~m} / \mathrm{s}$ can be achieved through the actualization of the same thrust value $\sim 90 \mathrm{kN}$, but by different methods: a) horizontal thrust (point 1 in Figure 2); b) thrust is inclined at angle $\beta=79.8^{\circ}$ to the horizon, providing full hovering of the vehicle (point 8 in Figure 2).

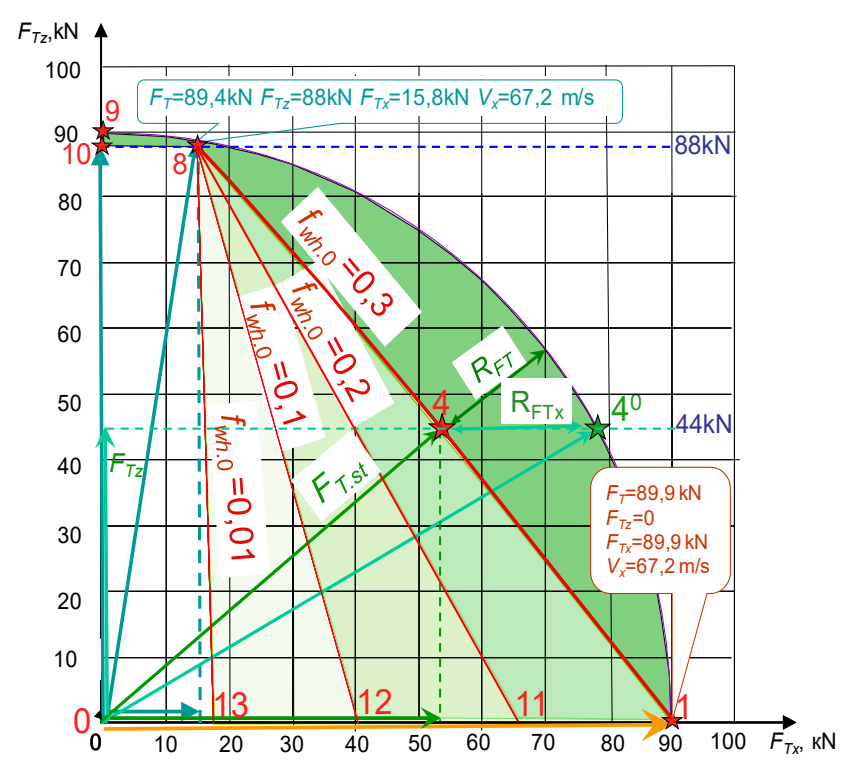

Figure 2. Diagram of force balance and possible use of thrust upon quantomobile motion along the bearing surfaces with $f_{\kappa 0}=0.3 \ldots 0.01$ at a speed of $67.2 \mathrm{~m} / \mathrm{s}$

The following question arises: what value and direction shall thrust take to maintain the speed of $67.2 \mathrm{~m} / \mathrm{s}$ upon partial hovering? The answer can be obtained from Table 1 and Figures 2 and 3 . Let us state that upon partial hovering $\left(\gamma=0.4 \ldots 0.7, \beta=30 \ldots 60^{\circ}\right)$ the thrust required to maintain the set speed shall be $15-25 \%$ less than in extreme cases: $\gamma \approx 0$ and $\beta \approx 0^{\circ}$, or $\gamma \approx 1$ and $\beta \approx 90^{\circ}$ (see a red curve in Figure 3 ). If constant thrust is maintained (e.g. $90 \mathrm{kN}$ ), then the maximum speed of steady motion can also be achieved upon intermediate hovering $\left(\left(g=0.7-0.9-\right.\right.$ see a blue curve for $V_{x \cdot \max }$ in Figure 3$)$. 
Table 1

Thrust characteristics in case of quantomobile motion along the surface with $f_{w h .0}=0.3$

\begin{tabular}{|c|c|c|c|c|c|c|c|c|c|c|}
\hline \multirow{2}{*}{$\begin{array}{l}\text { Point No. } \\
\text { in } \\
\text { Figure } 2\end{array}$} & \multirow[t]{2}{*}{ Hovering rate $\gamma$} & \multirow{2}{*}{$\begin{array}{c}\text { Maximum } \\
\text { speed, } \mathbf{m} / \mathbf{s}\end{array}$} & \multicolumn{7}{|c|}{ Thrust components, $\mathbf{k N}$} & \multirow{2}{*}{$\begin{array}{c}\text { Thrust } \\
\text { inclination } \\
\text { angle } \\
\text { relative to } \\
\text { the horizon, } \\
\text { degrees } \\
\beta_{s t}\end{array}$} \\
\hline & & & $F_{T z}$ & $F_{T \times, a c}$ & $F_{T X . S T}$ & $R_{F T X}$ & $F_{T . s t}$ & $R_{F T}$ & $\beta_{a c}$ & \\
\hline 1 & 0 & 67.2 & 0 & 90 & 89.89 & 0.11 & 89.9 & 0.11 & 0 & 0 \\
\hline 4 & $1 / 2$ & 86.4 & 44 & 78.52 & 52.85 & 25.7 & 68.7 & 21.23 & 29.26 & 39.8 \\
\hline 8 & 1 & 67.2 & 88 & 18.87 & 15.80 & 3.07 & 89.4 & 0.59 & 77.90 & 79.8 \\
\hline
\end{tabular}

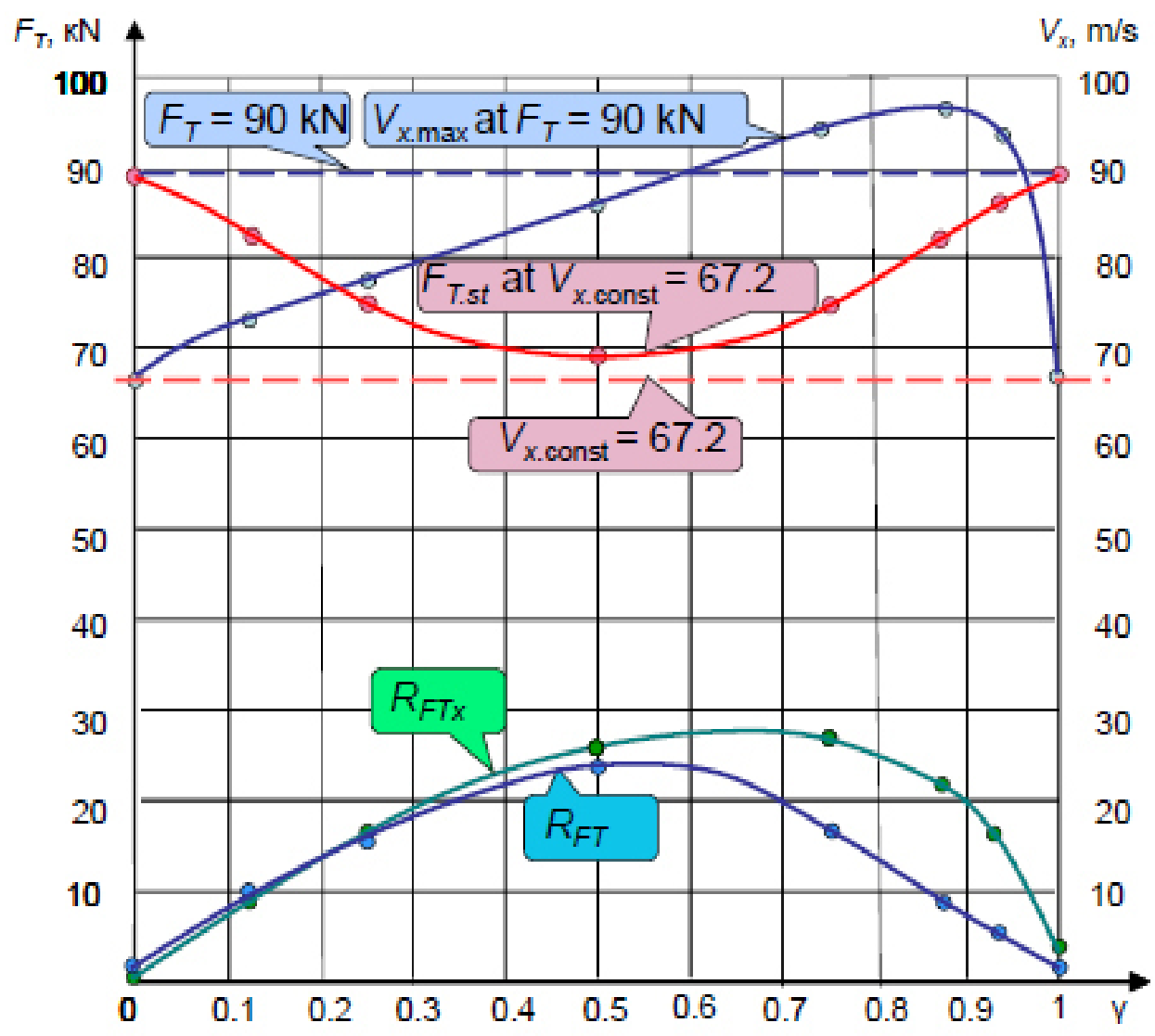

Figure 3. Dependence of motion characteristics on the vehicle hovering rate

The following designations are taken in Table 1 and in Figures 2 and 3:

$F_{T x . a c}-$ a horizontal component of the maximum thrust that ensures the set rate of vehicle hovering, speed $(67.2 \mathrm{~m} / \mathrm{s})$ maintenance, and the possibility of further acceleration;

$F_{T x \text { st }}$ - a horizontal component of the sufficient thrust, necessary and sufficient to maintain the steady speed of the vehicle of $67.2 \mathrm{~m} / \mathrm{s}$;
$R_{F T x}$ - the difference between the values $\left(F_{T x . a c}-F_{T x . s t}\right)$ that ensures further horizontal acceleration ax when the speed of the vehicle of $67.2 \mathrm{~m} / \mathrm{s}$ is achieved;

$F_{T . s t}-$ sufficient thrust to maintain the steady speed of $67.2 \mathrm{~m} / \mathrm{s}$;

$R_{F T}$ - the difference between the vector values $\left(F_{T}-\right.$ $\left.F_{T . S t}\right)$ that can ensure acceleration of the vehicle (ax and/ or az) when the horizontal speed of the vehicle of $67.2 \mathrm{~m} / \mathrm{s}$ is achieved; 
$\beta_{\mathrm{ac}}-$ maximum FT thrust angle relative to the horizon; $\beta_{\text {st }}^{\text {ac }}-$ sufficient FT.st thrust angle relative to the horizon.

An algorithm to calculate the mentioned values is provided in one of the author's articles (Kotikov, 2019c).
To analyze changes in this picture, caused by the changing vehicle speed, it is necessary to turn to speed characteristics. Let us consider a form accepted for automobile force balance (Figure 4).

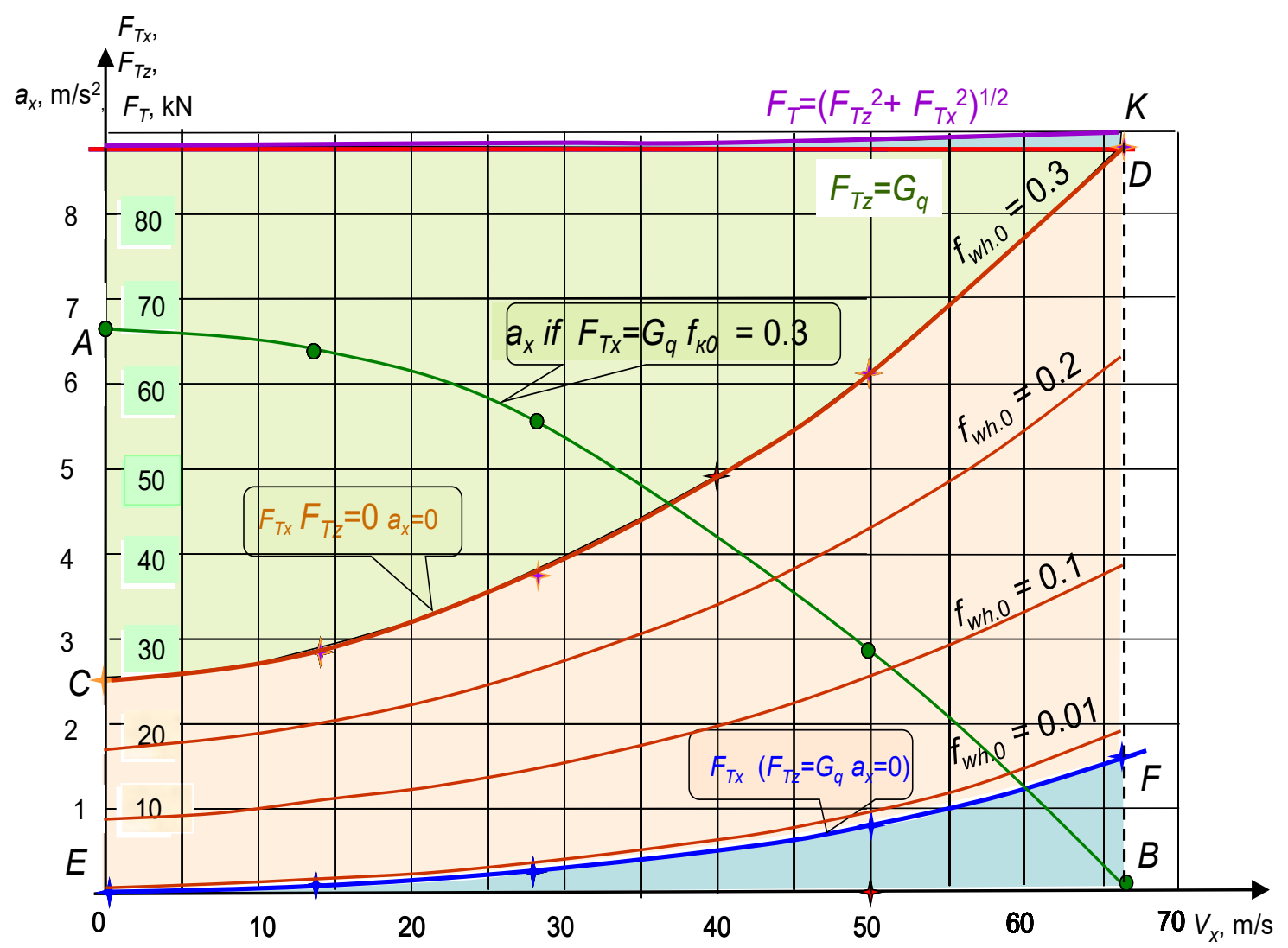

Figure 4. Speed characteristic curve with regard to the force balance of the quantomobile moving along the bearing surfaces with $f_{\text {wh.o }}=0.01-0.3$

For $f_{\text {wh.o }}=0.3$, three zones are highlighted in color in Figure 4: wind resistance (blue), resistance of the bearing surface (beige), remaining vehicle acceleration margin (green). The Figure also shows the acceleration curve $A B$ upon complete depletion of the thrust margin highlighted in green.

\section{D modeling of the quantomobile force balance}

It is possible to combine the capabilities of the diagrams in Figures 2 and 4 with the help of a 3D model. Let us build a 3D model using Maple software. Let us decompose the $F_{T}$ thrust vector into two orthogonal components $F_{T \times}$ and $F_{T Z}$, and direct the vehicle speed axis normally to the plane $F_{T x}-F_{T z}$. Let the de-identified variables be $F_{T x}=x, F_{T z}=z$, and $V_{x}=y$.

We programmed equations (5-9) to be used in the Maple environment in the form of $F_{T}^{2}=f(x, y, z)$ implicit function (see (5)) as well as coordinate functions $x=f(y, z)$, $z=f(x, y), y=f(x, z)$ (see (6-8)). Final graphic images were similar; however, differences in build time, specifics of coloration and surface grids were observed. The following explicit model was chosen by the mentioned factors as a basic one:

$$
z=f(x, y) \text {, i.e. } F_{T z}=f\left(F_{T x}, V_{x}\right) \text {. }
$$

The simple graphic images are given in Figure 5.

$F_{T \cdot \max }^{2}=F_{T x \cdot \max }^{2}+F_{T z \cdot \max }^{2}$ cylindrical surface representing QE limit capabilities is highlighted here (and below) in blue. The sum of wind resistance and bearing surface resistance to vehicle motion (corresponding surface) is highlighted in red.

The isolines correspond to tens of $\mathrm{kN}$ of the vertical component of thrust. Surfaces related to lower resistances to the rolling of wheels $f_{w h} .0$ occupy the half-space to the left of the red surface of the thrust required for steady motion. $\mathrm{QE}$ power for vehicle acceleration and maneuvering occupies the half-space to the right of the red surface of thrust (up to the cylindrical surface of maximum thrust). All future studies on searches for optimal trajectories shall be performed in this spatial domain.

It can be seen that the line segment between points 10 and 8 in Figure 2 corresponds to the force of wind resistance $P_{w}=15.8 \mathrm{kN}$. This value is constant for a particular slice of velocity. With changes in the resistance of the bearing surface $\left(f_{w h .0}=\right.$ var), 8-1 line inclination will 
change as well. Moreover, due to the stable position of point 8, line 8-1 will rotate about it. Dependence between the position of the surface of the required thrust and $f_{\text {who }}$ coefficient can be seen in Figure 6.

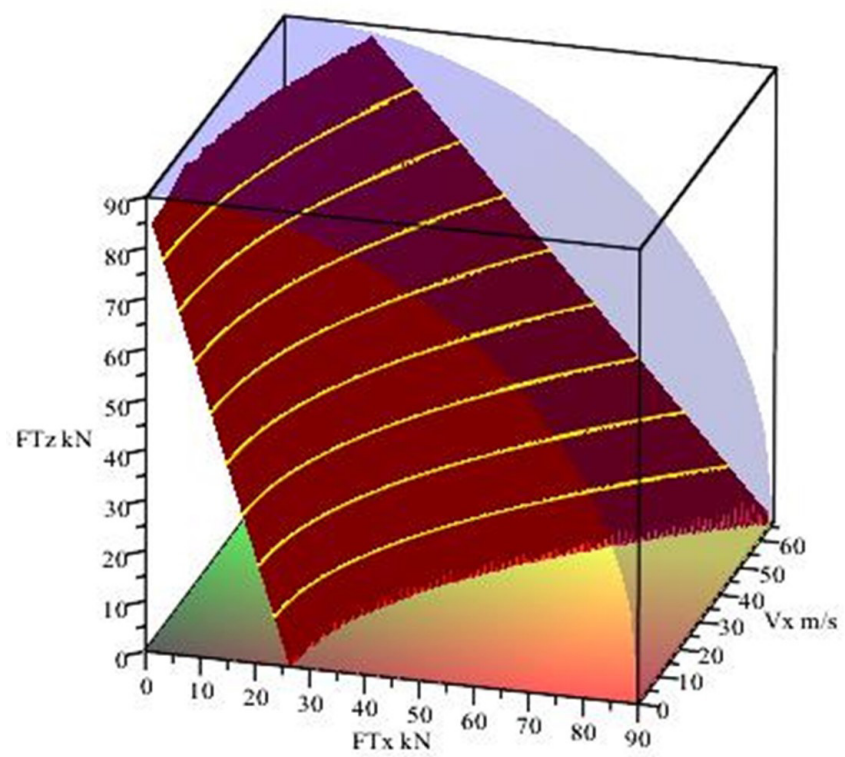

Figure 5. Surfaces: maximum QE thrust (blue, cylindrical) and thrust required for steady motion along the bearing surface with the coefficient of resistance $f_{\text {wh.o }}=0.3$ (red)
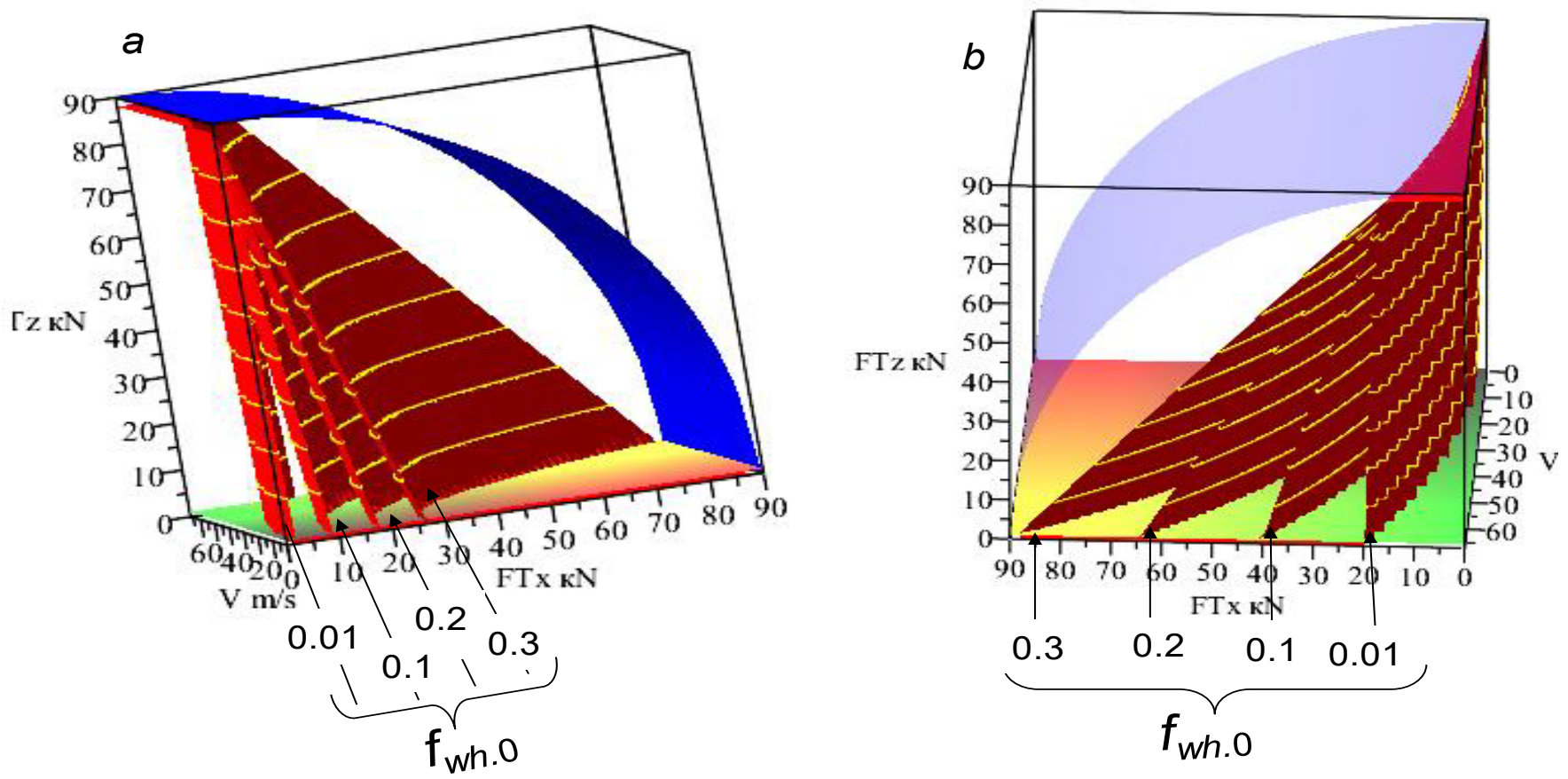

Figure 6 . Surfaces of the thrust required for steady motion of a quantomobile on roads with various $f_{w h \cdot{ }_{0}}$ coefficients

The addition of resistance to the rolling of wheels and wind resistance, resulting in total resistance to uniform longitudinal motion of a vehicle, is represented in a model based on equation (6). It is graphically shown in Figure 7. Forces of wind resistance (area to the left of the blue surface) and resistance to the rolling of wheels (area between the blue and red surfaces) are added to form total resistance to uniform vehicle motion (red surface). The area limited by the red and blue surfaces is a subspace for the use of thrust for vehicle acceleration and maneuvering. 


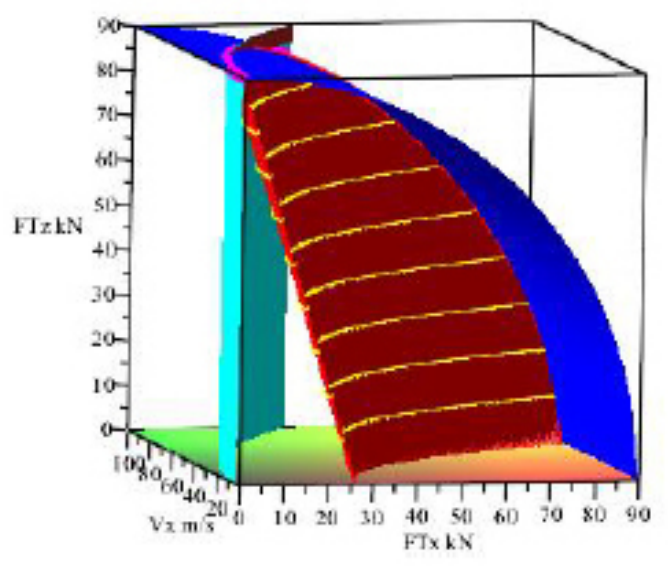

Figure 7. Addition of forces of wind resistance (to the left of the blue surface) and resistance to the rolling of wheels (between the blue and red surfaces), forming total resistance to vehicle motion (red surface).
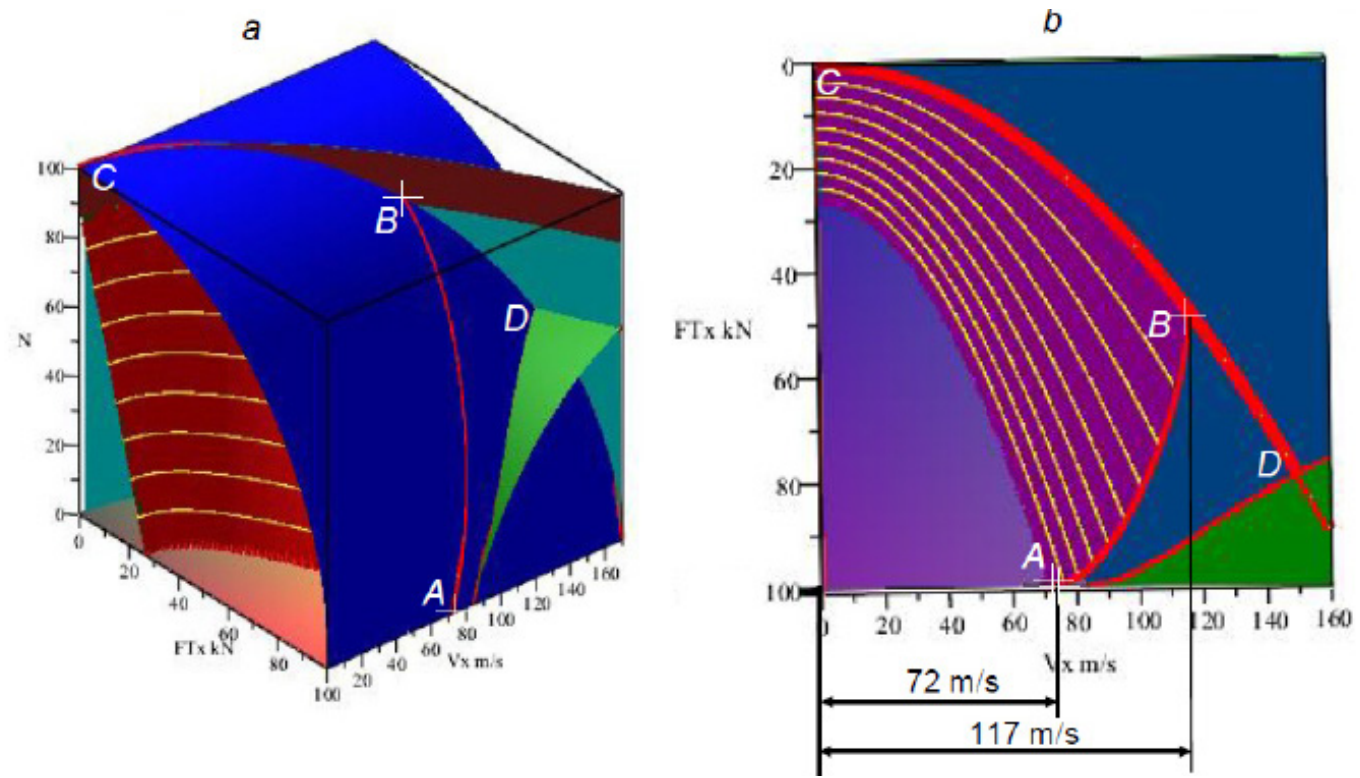

Figure 8. Set of surfaces and lines in the developed model: one of the options

\section{Results}

The main result of the study is a graphical-and-analytical basis for optimization calculations of quantomobile motion, changes in QE thrust and corresponding control actions. Its analytical component is a generalized quantomobile force balance equation taking into account the decomposition of the thrust vector into orthogonal component, which is a key element when determining optimal combinations of energy consumption for vehicle hovering and gains from a decrease in driven wheels resistance upon such hovering. While in case of aircrafts and helicopters, vertical takeoff (VTOL) and short takeoff (STOL) modes represent a small share of their relatively long-lasting operation, for quantomobile, near-ground motion can be the main long-term mode. Therefore, it is important to search for optimal combinations of the vertical and horizontal thrust components.

Maple software tools provide a rotating view of graphical 3D images, allow for interactive model modification, creation of animations. Besides the mentioned graphical functions, numerous additional options embedded in the model can be noted: surface intersection lines, surface limits along those lines, and surface extension outside the set limits (Figure 8). 
With this figure as an example, the following conclusion can be drawn: if a quantomobile with the indicated characteristics and QE with a maximum thrust of $100 \mathrm{kN}$ moves along the bearing surface with $f_{\text {wh.o }}=0.3 \mathrm{in}$ the automobile mode (without hovering), it is possible to achieve speed $V_{x}=72 \mathrm{~m} / \mathrm{s}$, while the maximum achievable speed upon partial hovering $V_{x}=117 \mathrm{~m} / \mathrm{s}$ (Figure $8 b$ ). In the first case, point $A$ represents an "exit" of line $A B$ (intersection of the red surface of the required thrust and blue surface of the QE maximum thrust) onto the plane $F_{T z}=0$. In the second case, point $B$ represents a point of intersection between line $A B$ and line $C D$ (intersection of the blue ( + brown in the upper part) surface of wind resistance with the dark blue surface of maximum thrust).

Therefore, at the same thrust, the maximum speed of a vehicle upon partial hovering is $50 \%$ more than the speed of a vehicle in the automobile mode, and that is due to the thrust vector direction only.

\section{Discussion}

Maple software is a powerful and flexible system with a wide mathematical apparatus, multi-parameter analytics of problem solving, and nice business graphics. It may seem that due to the lack of a real object being modeled (quantomobile), we are actually using a sledgehammer to crack a nut. However, its deep understanding is possible only with the use of such powerful tools.

Development of the quantomobile simulation model as well as its graphical-and-analytical basis in the direction of increasing complexity is the only way. At the next stage, it is required to program the generalized equation of qauntomobile motion, turn to differential models of vehicle motion, introduce a model of QE control, then turn to optimization models of trajectory control, develop special quantomobile aerodynamics, combine course and lateral motion, and, finally, switch to the concept of a "flying saucer". At all those stages, it will be necessary to form a graphical-and-analytical basis using Maple software tools.

Exit from the mode of near-ground motion is ensured by inequation $F_{T z}>G_{q}$. Several tests with the use of the model showed the following: in case of road resistance disappearance (at $F_{T Z}>G_{q}$ ), the formation of the second zone of thrust minimization is possible. A vehicle passes some crest in the force balance, which is related to hovering in the area $\gamma \approx 0.8 \ldots 1.0$. The latter circumstance is likely to matter when choosing a type of quantomobile takeoff: vertical (VTOL), short (STOL), or combined.

The numerical examples are based on the use of geometry, weight and aerodynamics parameters of similar KamAZ-4326. On the one part, this racing truck with more than a thousand HP happened to be the most similar to the hypothetical laboratory quantomobile (Kotikov, 2018b) in terms of force balance (Kotikov, 2018c, 2019a). On the other part, the mentioned parameters (in particular, aerodynamics parameters) will be unsatisfactory for the quantomobile. In that respect, all numerical examples and graphical images presented in this paper characterize the worst options of force balance and required thrust. Nevertheless, high design speeds of quantomobile near-ground motion (117 m/s and more) are due to the quantomobile thrust, which exceeds the automobile thrust significantly (Kotikov, 2018c, 2019a).

\section{Conclusions}

Based on the generalized quantomobile force balance equation (derived by the author), the graphical-andanalytical basis was developed to study quantomobile near-ground motion. The calculations, analysis, and visualization were based on the equation implementation in the Maple environment.

According to the calculation studies, in the middle of the full range of thrust vector inclination angles $\left(0-90^{\circ}\right)$, a zone of the most beneficial use of thrust upon partial hovering of a vehicle is located. This creates opportunities for developing methodologies to substantiate thrust control when a vehicle interacts with the bearing surface.

The Maple graphical tools allowed us to perform a visual analysis of the space topology with regard to thrust resources in a vehicle with a $\mathrm{QE}$, and confirm the possibility of using the software analytical tools in further studies.

At the current stage (with the simplest linear algebraic model for vehicle interaction with the road and simplified aerodynamics of the "flying box"), the first step of quantomobile near-ground modeling using Maple can be considered sufficient and adequate. 


\section{References}

Brandenburg, J. (2017). The GEM theory of energy and momentum exchange with spacetime, and forces observed in the Eagleworks Q-V thruster. In: Proceedings of the Estes Park Advanced Propulsion Workshop,19-22 September 2016, Estes Park, Colorado, USA. Mojave, CA: Space Studies Institute, Inc. Press. Available at: http://ssi.org/wp-content/uploads/2017/02/ssi_estes_park_proceedings_201609.pdf.

(accessed on: 14.09.2019).

Century of Flight (2007). VTOL and STOL aircraft. Available at: https://yandex.ru/images/search?text=Century\%20of\%20 Flight\%20(2007).\%20VTOL\%20and\%20STOL\%20aircraft\&stype=image\&/r=2\&source=wiz. (accessed on: 10.09.2019).

Cerbe, T., Reichert, G. (1989). Optimization of helicopter takeoff and landing. Journal of Aircraft, 26 (10), pp. 925-931. DOI: $10.2514 / 3.45863$

Kotikov, Ju.G., Lozhkin V.N. (2006). Transport energetics. Moscow: Academia Publishing Center, 272 p.

Kotikov, Ju. (2018a). Structural Properties and Operational Philosophy of the Vehicle with the Quantum Engine. Architecture and Engineering, 3 (1). pp. 13-20. DOI: 10.23968/2500-0055-2018-3-1-13-20.

Kotikov, Ju. (2018b). Stages Of Quantomobile Development. Architecture and Engineering, 3 (2), pp. 26-35. DOI: 10.23968/2500-0055-2018-3-2-26-35.

Kotikov, Ju. (2018c). Quantomobile: research of formation and imposition of thrust. Bulletin of Civil Engineers, 4, pp. 189-198. DOI: 10.23968/1999-5571-2018-15-4-189-198.

Kotikov, Ju. (2019a). Traction-speed properties of the quantomobile. Bulletin of Civil Engineers, 1, pp. 168-176. DOI: 10.23968/1999-5571-2019-16-1-168-176.

Kotikov, Ju. (2019b). Specifics of the Quantomobile Force Balance. Architecture and Engineering, 4 (1), pp. 3-10. DOI: 10.23968/2500-0055-2019-4-1-3-10.

Kotikov, Ju. (2019c). Actualization of the Quantomobile Force Balance in the Pitch Plane. Architecture and Engineering, 4 (2), pp. 53-60. DOI: 10.23968/2500-0055-2019-4-2-53-60.

Leonov, V.S. (2002). Patent No. 2185526 (Russian Federation). A method of thrust generation in vacuum and a field engine for spaceship (options). Bulletin No. 20 dd. 20.07.2002 (priority date: 21.05.2001).

Leonov, V.S. (2010). Quantum Energetics. Vol. 1. Theory of Superunification. Cambridge: Cambridge International Science Publishing, 753 p. Available at: https://drive.google.com/file/d/1PNclxVYBuD1BkBOaGlndyjulHc_coNvb/view (accessed on: 10.09.2019).

Leonov, V.S. (2018). Fundamentals of the theory of reactive and non-reactive thrust. Available at: https://drive.google.com/ file/d/1ZPHqpyZOhjovwWxbvuRpOV_yRVu2yt0F/view (accessed on: 10.09.2019).

Schmitz, F.H. (1971). Optimal Takeoff Trajectories of a Heavily Loaded Helicopter. Journal of Aircraft, 8 (9), pp. 717-723. DOI: $10.2514 / 3.59162$

Tajmar, M., Kößling M., Weikert M., Monette M. (2007). The SpaceDrive Project - First Results on EMDrive and Mach-Effect Thrusters. Available at: https://tu-dresden.de/ing/maschinenwesen/ilr/rfs/ressourcen/dateien/forschung/folder- 


\title{
ГРАФОАНАЛИТИЧЕСКИЙ БАЗИС ИССЛЕДОВАНИЯ ПРИЗЕМНОГО ДВИЖЕНИЯ КВАНТОМОБИЛЯ
}

\author{
Юрий Георгиевич Котиков \\ Санкт-Петербургский государственный архитектурно-строительный университет \\ 2-ая Красноармейская ул., 4, г. Санкт-Петербург, Россия \\ E-mail: cotikov@mail.ru
}

\section{Аннотация}

Введение. Продвижению исследовательских работ по созданию квантомобиля будет способствовать создание графроаналитического базиса для оптимизационных расчетов управления движением этого транспортного средства. Цель. Сформировать методику графического отображения области реализации вектора траста (thrust) - как графоаналитического базиса для будущих оптимизационных расчетов траекторий движения квантомобиля. Методы. Разложение вектора траста на ортогональные компоненты. Использование обобщенного уравнения силового баланса квантомобиля и его упрощения. Определение 6 характерных режимов движения квантомобиля, выделение из них режима частичного вывешивания как основного в приземном движении. 2D-моделирование силового баланса для скоростного среза. 3D-моделирование силового баланса с разверткой по скорости. Программирование 2D и 3D моделей силового баланса в ППП Maple. Построение образов поверхностей сопротивлений дороги и аэродинамических сил, максимального и достаточноготраста. Расчетные играфоаналитическиеисследованиянапримерах. Результаты. Сформирован графоаналитический базис для оптимизационных расчетов траекторий движения квантомобиля, изменения траста его КвД и соответствующих управляющих воздействий. Представлены результаты вычислений с визуализацией на конкретных примерах. Обсуждение. Создание программы в среде графического ППП потребовало комплексирования знаний как средств пакета, так и программируемой области знаний. Естественным будет путь развития расчетной модели квантомобиля и его графоаналитического базиса по пути возрастающей сложности, приводятся этапы развития. Отмечены две предположительные зоны минимизации достаточного траста: в срединной части степени вывешивания экипажа и после его полного вывешивания. Это необходимо учитывать при реализации как взлета квантомобиля, так и при приземном движении с частичным вывешиванием.

\section{Ключевые слова}

Квантовый двигатель, квантовая тяга, квантомобиль, приземное движение, силовой баланс, графоаналитический базис 